\title{
Copper and Resveratrol Attenuates Serum Catalase, Glutathione Peroxidase, and Element Values in Rats with DMBA-Induced Mammary Carcinogenesis
}

\author{
Dorota Skrajnowska • Barbara Bobrowska-Korczak • \\ Andrzej Tokarz • Slawomir Bialek • Ewelina Jezierska • \\ Justyna Makowska
}

Received: 31 July 2013 / Accepted: 25 October 2013 / Published online: 12 November 2013

(C) The Author(s) 2013. This article is published with open access at Springerlink.com

\begin{abstract}
In this paper, a hypothesis was assessed whether or not the intoxication with copper and supplementation with copper plus resveratrol would result in changes in the activities of catalase and glutathione peroxidase and moreover if the characteristic changes would appear in concentrations of copper, iron, calcium, magnesium, and zinc in the serum of rats with chemically induced carcinogenesis. Female SpragueDawley rats were divided into study groups which, apart from the standard diet, were treated with copper $(42.6 \mathrm{mg} \mathrm{Cu} / \mathrm{kg}$ food as $\left.\mathrm{CuSO}_{4} \cdot 5 \mathrm{H}_{2} \mathrm{O}\right)$ or copper plus resveratrol $(0.2 \mathrm{mg} / \mathrm{kg}$ body) via gavage for a period from 40 days until 20 weeks of age. In cancer groups, the rats were treated with a dose of $80 \mathrm{mg} /$ body weight of 7,12-dimethyl-1,2-benz [a $]$ anthracene (DMBA) given in rapeseed oil at 50 and 80 days of age to induce mammary carcinogenesis. The control groups included the rats kept in the same conditions and fed with the same diet as the animals from the study groups, but not DMBA-treated. The activity of catalase significantly decreased in groups of rats with mammary carcinogenesis that were supplemented with copper $(p<0.05)$ or copper plus resveratrol $(p<0.001)$ in comparison with the control groups that received the same diets. In cancer groups of nonsupplemented rats, the increase of glutathione peroxidase activity was observed. The process of carcinogenesis and the applied supplementation significantly altered the concentrations of trace elements in serum, in particular as concerns iron and copper. The mean serum iron
\end{abstract}

D. Skrajnowska • B. Bobrowska-Korczak $(\bowtie) \cdot$ A. Tokarz E. Jezierska $\cdot$ J. Makowska

Department of Bromatology, Medical University of Warsaw, Banacha 1, 02-097 Warsaw, Poland

e-mail: barbara.bobrowska@wum.edu.pl

S. Bialek

Department of Biochemistry, Medical University of Warsaw, Banacha 1, 02-097 Warsaw, Poland levels in rats with breast cancer were significantly lower than those in the control groups $(p<0.001)$. The mean serum copper levels significantly decreased in the groups of rats with mammary carcinogenesis that were supplemented with copper or copper plus resveratrol in comparison with the control groups that received the same diets $(p<0.001)$. The characteristic changes in iron content and the zinc/copper and zinc/ iron ratios in blood may be used as one of the prognostic factors in breast cancer research.

Keywords Copper · Resveratrol - Serum mineral analysis . Catalase $\cdot$ Gluthatione peroxidase $\cdot$ Breast cancer

\section{Introduction}

Copper intoxication and supplementation with a carcinogen are both the factors that can induce oxidative stress in living organisms thus leading to an increased concentration of reactive oxygen species (ROS) which have a destructive effect on cells [1]. Inactivation of ROS can be carried out by antioxidative enzymes [2-5]. The enzymatic antioxidants include superoxide dismutase, catalase, and glutathione peroxidase. Hydrogen peroxide formed by the catalytic reaction of superoxide dismutase is both a reactive form of oxygen and a normal cellular metabolite, and it is further detoxified to water by glutathione peroxidase and catalase [6]. Elements have been shown to exert protective effects against cancer-induced oxidative stress injury by acting as cofactors for several enzyme antioxidant systems [7]. For example, iron and selenium are essential trace elements for humans and are cofactors for catalase and glutathione peroxidase, respectively. Copper is generally considered as a pro-oxidant metal which participates in Fenton-like reactions. One of the mechanisms of the precancerous copper activity involves its ability to produce a 
strongly reactive hydroxyl radical responsible for oxidative damage to DNA strands and also peroxidation of cell membrane lipids $[8,9]$. However, in the case of the already existing neoplastic process, the oxidative properties of copper can be directed against cancer cells. During the last few decades, numerous investigations have shown that neoplastic cells, as compared with healthy cells, are characterized by a much higher level of oxidative stress, which is probably the result of their increased metabolism, the presence of mitochondrial mutations, numerous cytokines, and inflammatory disease. However, the equilibrium between the number of ROS and the decreased number of antioxidants is not so much disturbed as to cause their death by apoptosis or necrosis. The investigations however resulted in further attempts at developing another strategy in cancer therapies, based on increasing the ROS level, which would kill the neoplastic cells without affecting the healthy cells, as it is assumed that the healthy cells probably possess a satisfactory number of antioxidants to protect the body against the excessive amount of ROS [9]. As is well known, resveratrol can induce the apoptosis of cancer cells, inhibiting their invasion by affecting a number of various factors, including slowing down tumor angiogenesis [10-12]. Resveratrol can also exhibit antioxidative activity and can function as a certain "prooxidizer," particularly in the presence of copper ions (reduction of $\mathrm{Cu}^{2+}$ ions to $\mathrm{Cu}^{+}$ions stimulates the production of free radicals $[13,14])$. In this case, both the increased oxidative stress and the higher copper level may pertain to a selective treatment of the neoplastic disease.

However, generally, it can be said that because of different dietary habits in patients, it is rather difficult to correlate the changes in mineral levels in serum with the already existing cancer process. Whereas in the animal model, while making use of the selective pro-cancer potential of DMBA as inducing mammary carcinogenesis, it is possible to investigate the effect of the neoplastic disease and selected diet on such parameters as the activity of antioxidative enzymes or the concentration of selected minerals in the serum.

\section{Materials and Methods}

Animals

The female Sprague-Dawley rats of body mass $\pm 210 \mathrm{~g}$ were kept in constant, controlled conditions (temperature $22 \pm 1^{\circ} \mathrm{C}$, with a 12-h day/night cycle) with free access to water and laboratory food Labofeed $\mathrm{H}$ (produced by Morawski, Kcynia, Poland). The investigations obtained ethical approval from the Ethics Committee at Warsaw Medical University.

\section{Groups}

The rats were divided into a study group $(n=26)$ and a control group $(n=19)$. To induce mammary tumorigenesis, the animals from the study group were administered 7,12-dimethyl-1,2-benz $[a]$ anthracene (DMBA; Sigma-Aldrich, St. Louis, MO, USA) via gavage in rapeseed oil at a dose of $80 \mathrm{mg} / \mathrm{kg}$ body weight at 50 and 80 days of age. The control groups included the rats kept in the same conditions and fed with the same diet as the animals from the study groups, but not DMBA-treated. The following diets were used:

Diet 1 standard fodder Labofeed $\mathrm{H}$ (containing $21.3 \mathrm{mg} \mathrm{Cu}$ / $\mathrm{kg}$ food) and $0.4 \mathrm{~mL}$ water daily via gavage (study group DMBA+ and control group DMBA-)

Diet 2 copper fodder Labofeed $\mathrm{H}+$ copper supplementation at a dose of $42.6 \mathrm{mg} \mathrm{Cu} / \mathrm{kg}$ food (as $0.51 \mathrm{mg}$ $\mathrm{CuSO}_{4} \cdot 5 \mathrm{H}_{2} \mathrm{O}$ in $4 \mathrm{~mL} \mathrm{H}_{2} \mathrm{O}$ ) via gavage (study group DMBA+ and control group DMBA-),

Diet 3 copper + resveratrol fodder Labofeed $\mathrm{H}+\mathrm{Cu}$ supple mentation at a dose of $42.6 \mathrm{mg} \mathrm{Cu} / \mathrm{kg}$ food (as $0.51 \mathrm{mg} \mathrm{CuSO}{ }_{4} \cdot 5 \mathrm{H}_{2} \mathrm{O}$ in $4 \mathrm{~mL} \mathrm{H}_{2} \mathrm{O}$ ) and resveratrol at a dose of $0.2 \mathrm{mg} / \mathrm{kg}$ body weight (as $0.04 \mathrm{mg}$ resveratrol in $0.4 \mathrm{~mL}$ $\mathrm{H}_{2} \mathrm{O}$ ) via gavage (study group DMBA+ and control group DMBA-).

The rats were fed with the above diets from 40 days until 20 weeks of age (sacrifice time by decapitation). The dose level of resveratrol was selected based on the average daily polyphenol consumption by consumers $(15 \mathrm{mg} /$ day $)$ [15] (extrapolating to the rat's body weight). The dose of copper was established as the double content of this mineral in the food Labofeed H [16]. In order to obtain samples for investigations, the rats were sacrificed by decapitation on 20 week of age.

\section{Blood Collection and Preparation}

In the investigations, we used the serum of rats, obtained as a result of centrifugation of whole blood collected from the rats (2500 rpm for $15 \mathrm{~min}$ ). The serum samples were stored in a deep freezer at $-80{ }^{\circ} \mathrm{C}$ until performing the investigations. Before the determinations, the serum was thawed and then again centrifuged at $2500 \mathrm{rpm}$ for $15 \mathrm{~min}$.

Catalase activity in the serum of rats was determined by the test Catalase Assay Kit by Cayman. Determinations of peroxidase activity were performed using the test Glutathione Peroxidase Assay Kit Chemical Company.

Cayman's catalase assay (Cayman Chemical Company Ann Arbor, MI 48108) utilizes the peroxidatic function of catalase for the determination of enzyme activity. The method is based on the reaction of the enzyme with methanol in the presence of an optimal concentration of hydrogen peroxide. The formaldehyde produced is measured colorimetrically with 4-amino-3-hydrazino-5-mercapto-1,2,4-triazole (purpald) as the chromogen. Purpald specifically forms a bicyclic 
heterocycle with aldehydes, which upon oxidation changes its color from colorless to purple (the absorbance at $540 \mathrm{~nm}$ ).

Cayman's Glutathione Peroxidase Assay (Cayman Chemical Company Ann Arbor, MI 48108) measures glutathione peroxidase activity indirectly by a coupled reaction with glutathione reductase (GR). The oxidized glutathione (GSSG), produced upon the reduction of hydroperoxide by glutathione peroxidase, is recycled to its reduced state by GR and NADPH. The oxidation of NADPH to $\mathrm{NADP}^{+}$is accompanied by a decrease in absorbance at $340 \mathrm{~nm}$. In conditions in which the glutathione peroxidase activity is rate limiting, the rate of decrease in absorbance is directly proportional to the glutathione peroxidase activity in the sample.

For determinations of the catalase and peroxidase activities, a Bio-Tek Instruments spectrophotometer, JNC, Highland Park, Box 998, Winooski UT 05404 - 0998, USA, was used.

\section{Element Analyses}

The determination of calcium, magnesium, zinc, and iron was carried out in serum samples by air-acetylene flame atomic absorption spectrometer (PU-9100). Before the mineral determinations, the serum was thawed and then centrifuged at $2500 \mathrm{rpm}$ for $15 \mathrm{~min}$. For the determination of minerals, serum samples of about $0.5 \mathrm{~mL}$ each were diluted with deionized water in the proportion 1:10 for $\mathrm{Zn}, \mathrm{Cu}$, and $\mathrm{Fe}$ and 1:70 for $\mathrm{Ca}$ and $\mathrm{Mg}$. Standard solutions of $\mathrm{Ca}, \mathrm{Mg}, \mathrm{Fe}, \mathrm{Zn}$, and $\mathrm{Cu}$ were prepared from their standard solutions $(1000 \mathrm{mg} / \mathrm{L}$ in water) from the Central Office of Measures, Warsaw, Poland).

\section{Recovery and Detection Limit}

The intralaboratory quality control of determination was based on the following certified reference material (percent of recovery for a given element and relative standard deviation (RSD).

- Seronorm Trace Elements Serum-1 (SERO201405): Cu $106 \%$, Fe $100 \%$, Ca $99 \%$, Zn $101 \%$, Mg $96 \%$

- $\quad$ RSDs: Cu 4 \%, Fe 4 \%, Ca $3.8 \%$, Zn $2.3 \%$, Mg $2.3 \%$

- Limits of detection (LOD) for Cu $0.18 \mathrm{mg} / \mathrm{L}, \mathrm{Fe} 0.38 \mathrm{mg} / \mathrm{L}$, Ca $0.25 \mathrm{mg} / \mathrm{L}, \mathrm{Zn} 0.01 \mathrm{mg} / \mathrm{L}, \mathrm{Mg} 0.12 \mathrm{mg} / \mathrm{L}$

\section{Statistical Analysis}

Statistical calculations were carried out using the Microsoft Excel program. The results are expressed as means \pm standard deviations and compared by the Student's $t$ test. In order to verify the results that aroused some doubts, Dixon's test was used. The statistical significance for the difference between the study and control groups was accepted at $p<0.05$.

\section{Results}

The results showed that catalase activity significantly decreased in cancer groups (DMBA+) supplemented both with copper only $(13.9 \mu \mathrm{mol} / \mathrm{min} / \mathrm{mL}$ vs $16.1 \mu \mathrm{mol} / \mathrm{min} / \mathrm{mL} ; p<0.05)$ and with copper plus resveratrol $(5.53 \mu \mathrm{mol} / \mathrm{min} / \mathrm{mL}$ vs $11.1 \mu \mathrm{mol} / \mathrm{min} /$ $\mathrm{mL} ; p<0001$ ) in comparison with the control groups (DMBA-) that received the same diets (Fig. 1). No changes in catalase activity were observed in the case of unsupplemented rats, fed with only a standard diet. In this group however, an increase in glutathione peroxidase activity was observed $(0.90 \mathrm{nmol} / \mathrm{min} /$ $\mathrm{mL}$ vs $0.75 \mathrm{nmol} / \mathrm{min} / \mathrm{mL} ; p<0.05$; Fig. 1).

The process of carcinogenesis and the applied supplementation significantly altered the concentrations of trace elements in serum, in particular as concerns the iron and copper. The mean serum iron levels in all rats with breast cancer were significantly lower than those in the control groups $(p<0.001)$. The mean serum copper levels significantly decreased in groups of rats with mammary carcinogenesis that were supplemented with copper or copper plus resveratrol in comparison with the control groups that received the same diets $(p<0.001)$.

In the group of rats fed with a standard diet and supplemented with copper, an increase of calcium concentration was found $(p<0.02$ and $p<0.05)$.

Most changes in the levels of the examined minerals were observed in the serum of rats which were supplemented with copper plus resveratrol (Table 1). In addition, in that group, there occurred a decrease in the magnesium $(p<0.001)$ and zinc content $(p<0.001)$ in comparison with the animals without induced mammary carcinogenesis (Table 1).

Moreover, the zinc/copper ratio significantly decreased in the copper-supplemented groups $(0.53$ vs $1.25 ; p<0.001)$ and in the group supplemented with copper plus resveratrol $(0.70$ vs $4.54 ; p<0.001)$ in comparison with the respective control groups fed with the same diets (Fig. 2).

The zinc/iron ratio significantly increased in all cancer groups in comparison with the respective control groups that obtained the same diets (Fig. 2). Thus in the group of rats fed with a standard diet, the zinc/copper ratio was 0.46 vs 0.27 ( $p$ $<0.001$ ); in the copper-supplemented group, 0.47 vs 0.36 ( $p<$ $0.05)$; and in the group supplemented with copper plus resveratrol, 0.47 vs $0.31(p<0.001)$.

\section{Discussion}

In this article, three main problems were discussed. First of all, we wanted to find the answer to the question if the advanced neoplastic process affects the activities of antioxidative enzymes catalase and glutathione peroxidase in the serum of rats. Secondly, we wanted to find out if in the case of rats with mammary carcinoma, an additional diet supplementation with copper in the form of its aqueous solution $\mathrm{CuSO} 45 \mathrm{H} 2 \mathrm{O}$ and 


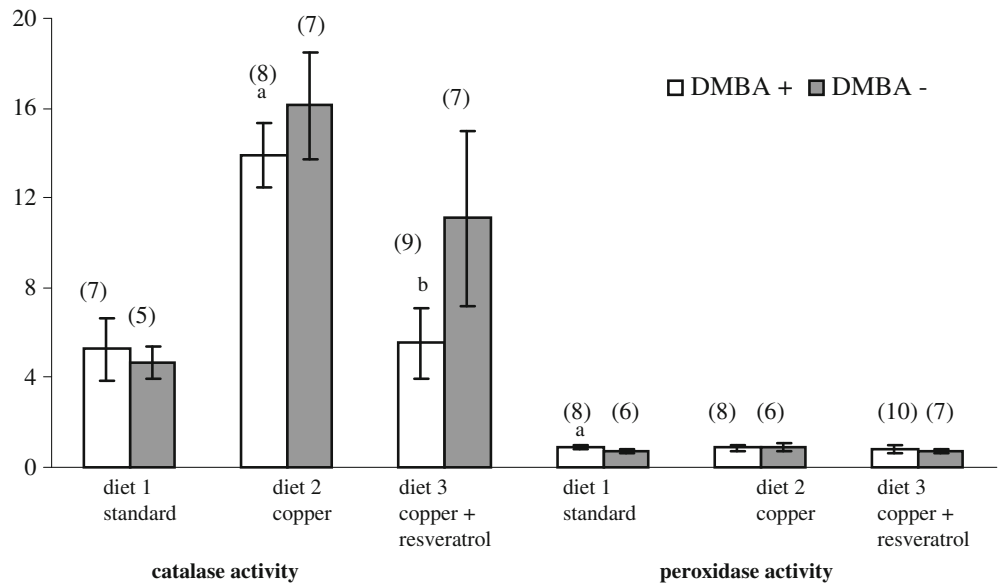

Fig. 1 A comparison of catalase activity $(\mu \mathrm{mol} / \mathrm{min} / \mathrm{mL})$ and peroxidase activity $(\mathrm{nmol} / \mathrm{min} / \mathrm{mL})$ in the serum of the examined rats with mammary cancer with respect to the control rats fed with the same diet. Numbers $0-20$ refer to the serum evaluated at 20 weeks of the animals' age (decapitation time). $D M B A$ 7,12-dimethyl-1,2-benz[ $a$ ]anthracene. $a$ statistically significant results of a comparison of the activities of enzymes in the serum of the $\mathrm{DMBA}+$ and DMBA- groups of rats receiving the same diet $(p<0.05) . b$ statistically significant results of a comparison of the activities of enzymes in the serum of the DMBA+ and DMBA - groups of rats receiving the same diet $(p<0.001)$. (n) test number also supplementation with copper plus resveratrol would cause any changes in the activity of the examined enzymes as compared with rats with no induced cancer. The third problem was focused on answering the question of whether or not a protracted neoplastic disease results in characteristic changes in the concentration and proportions of the examined minerals in the blood, which could become one of the prognostic factors of mammary carcinoma.

As concerns the first of the problems examined, during 14 days of studies, it was found that the catalase enzymatic activity was significantly lowered, especially in the group of rats that were supplemented with copper plus resveratrol, whereas it remained unchanged in the case of rats fed with a standard diet only (Fig. 1). Thus it seems that at 20 weeks of age for the rats in which the first mammary tumors were observed already during 14 weeks of age (data from earlier publications) $[17,18]$, the applied diet could be considered as the main factor responsible for the decrease of catalase activity.

DMBA exhibits selective cancer-inducing activity, in particular inducing mammary carcinoma; that is why, it is used as a standard carcinogen in investigations on this kind of cancer [19]. The mammary gland undergoes intensive functional and morphological series of changes as it develops. Barros et al. [19] found that the rats which were DMBA-treated when they started puberty (between 45 and 60 days of life) were most prone to develop mammary carcinoma. Then the mammary gland grows rapidly, and there occurs a high proliferation of types 1 and 2 lobules which are characterized by the highest DNA labeling index [19]. The DMBA-induced neoplastic process is based on many mechanisms. Firstly, carcinogenesis is induced by forming adducts of active metabolites from DNA; secondly, by generating the state of oxidative stress which is expressed by a decrease of the level of antioxidative

Table 1 The mineral content in the serum of the examined rats with mammary cancer as compared with the control rats fed with the same diet

\begin{tabular}{lllllll}
\hline Diets & & Copper $X \pm \operatorname{SD}(n)$ & Iron $X \pm \operatorname{SD}(n)$ & Calcium $X \pm \operatorname{SD}(n)$ & Magnesium $X \pm \operatorname{SD}(n)$ & Zinc $X \pm \operatorname{SD}(n)$ \\
\hline Diet 1 standard & DMBA+ & $0.80 \pm 0.24(8)$ & $2.86 \pm 0.53^{\mathrm{b}}(8)$ & $92.2 \pm 11.1^{\mathrm{a}}(8)$ & $19.2 \pm 1.3(8)$ & $1.25 \pm 0.1(7)$ \\
& DMBA- & $0.63 \pm 0.16(6)$ & $4.86 \pm 0.66(6)$ & $77.99 \pm 4.07(6)$ & $18.8 \pm 0.85(6)$ & $1.27 \pm 0.07(6)$ \\
Diet 2 copper & DMBA+ & $2.29 \pm 0.36^{\mathrm{b}}(7)$ & $2.58 \pm 0.49^{\mathrm{a}}(7)$ & $85.3 \pm 4.8^{\mathrm{a}}(8)$ & $18.5 \pm 1.5(8)$ & $1.18 \pm 0.07(7)$ \\
& DMBA- & $1.02 \pm 0.26(6)$ & $3.42 \pm 0.68(6)$ & $77.1 \pm 7.2(6)$ & $18.9 \pm 2.5(6)$ & $1.21 \pm 0.17(6)$ \\
Diet 3 copper+resveratrol & DMBA+ & $1.73 \pm 0.33^{\mathrm{b}}(9)$ & $2.61 \pm 0.55^{\mathrm{b}}(10)$ & $86.8 \pm 6.9(9)$ & $17.8 \pm 0.5^{\mathrm{b}}(9)$ & $1.140 .15^{\mathrm{b}}(10)$ \\
& DMBA- & $0.52 \pm 0.24(7)$ & $5.81 \pm 1.61(7)$ & $88.2 \pm 7.2(7)$ & $20.3 \pm 1.6(7)$ & $1.78 \pm 0.38(7)$ \\
\hline
\end{tabular}

$X$ mean, $S D$ standard deviation, $(n)$ test number

${ }^{\text {a }}$ Statistically significant results of a comparison of the minerals in the serum of the DMBA + and DMBA- groups of rats receiving the same diet $(p<$ $0.05)$

${ }^{\mathrm{b}}$ Statistically significant results of a comparison of the minerals in the serum of the DMBA+ and DMBA- groups of rats receiving the same diet $(p<0.001)$ 


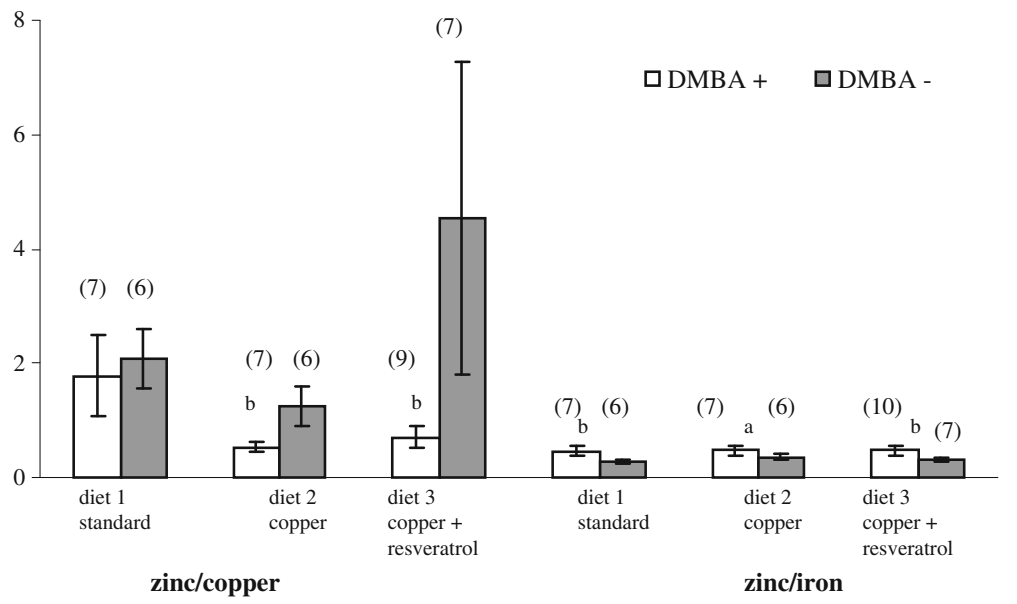

Fig. 2 Comparison of the changes in mineral ratio composition: $\mathrm{Zn} / \mathrm{Cu}$ and $\mathrm{Zn} / \mathrm{Fe}$ in the serum of rats with mammary cancer against the control rats. Numbers $0-8$ refer to the serum evaluated at 20 weeks of the animals' age (decapitation time). DMBA 7,12-dimethyl-1,2benz $[a]$ anthracene. $a$ statistically significant results of a comparison of

enzymes, such as catalase, superoxide dismutase, and glutathione peroxidase; furthermore, by blocking the liberation from the intestine of glutathione, an important antioxidant; or else by decreasing the activity of natural killer (NK) cells $[20,21]$. In a number of papers, the authors emphasize an enormous negative effect of DMBA on the rat genome, which occurs after administering even a single oral dose [19-21].

In our investigations in the group of rats fed with only a standard diet, there was no significant decrease of catalase activity (Fig. 1). However, as a result of the supplementation with copper or copper plus resveratrol, a decrease of catalase activity was observed and moreover the first palpable tumors appeared a week earlier than in the rats fed with a standard diet (data included in our earlier publication) [18]. On the basis of the observed results, it can be supposed that there occurred a synergistic carcinogenic activity of DMBA and copper ions. Although copper is a required element in the body, high concentrations appear to be toxic to organisms. The copper supplementation used in our investigations, exceeding twice the amount of this mineral in the fodder, did not cause any loss of appetite or loss of body weight in rats; moreover, in the group receiving copper plus resveratrol, this contributed to a considerable increase of body weight (data included in previous publications) $(17,18)$. Irrespectively of the applied diet, the effectiveness of cancer induction by DMBA was $100 \%$ $[17,18]$. The excess of copper ions can cause the oxidation of biologically important cell structures and, for instance, break the single DNA threads (even 50 times more rapidly than it is in the case of iron), or result in the rupture of the inner mitochondrial membrane (the loss of ATP cell supplies). It can also damage the cell membrane phospholipids during the peroxidation process $[9,14]$. As shown in our previous paper [22], the animals receiving the diet supplemented with copper the ratio of minerals in the serum of the DMBA+ and DMBA- groups of rats receiving the same diet $(p<0.05) . b$ statistically significant results of a comparison of the ratio of minerals in the serum of the DMBA+ and DMBA- groups of rats receiving the same diet $(p<0.001)$. (n) test number

or copper plus resveratrol had a significantly higher amount of 8 -isoPGF $2 \alpha$ in urine compared with animals receiving a standard diet. This implies a pro-oxidant effect of copper. Additionally, the copper has the ability of tumor angiogenesis, by activating a number of growth factors. And finally, it is worth mentioning once again that resveratrol in combination with copper can exhibit a pro-oxidative activity, as it was shown in the case of D-penicillamine which exhibits cytotoxic characteristics in the presence of copper [23]. The increase of the level of ROS can lead to effective destruction of cancer cells [23]. Thus the application of a factor stimulating the formation of ROS increases the oxidative stress in the cells to such a level that they undergo apoptosis. In this work, the application of copper in combination with resveratrol, on the one hand combining the toxic excess of copper, and on the other generating the excess of reactive oxygen species in the neoplastic cells, was going to cause apoptosis of cancer cells. However, both the number of tumors and the rate of their appearance were similar to those found in the group of rats supplemented with copper only [18]. In addition, in this group, there occurred a $50 \%$ decrease of catalase activity in comparison with the control group (Fig. 1). This means that in our experimental model, the use of resveratrol, a compound of well-known antioxidative and anticancer activities, and also of potential pro-oxidative activity in the presence of copper, did not have a positive, protective effect against cancer. It seems thus that the applied combined supplementation of copper with resveratrol does not meet expectations, even though the oral supply of resveratrol described in our earlier investigations significantly delayed (by 3 weeks) the appearance of mammary tumors, and also resulted in a decrease of their number and size [24]. The decrease of catalase activity, as observed in the present work, is characteristic of many diseases, including neoplastic 
diseases [25-27]. Many works report that copper inhibited the catalase activity and suggest that this inhibition is due to the deterioration of its enzymatic structure by reactive oxygen species mediated by copper or due to copper interference with their thiol groups $[28,29]$. During the last few years, there have been numerous attempts to characterize the chemopreventive and therapeutic potential of resveratrol. In order to determine the mechanism of activity of this compound, a lot of investigations were carried out on cell cultures of human neoplasms of various types [11-14]. In many works, it was found that resveratrol is able to induce apoptosis and to slow down the invasion and angiogenesis of neoplastic cells by different mechanisms. Besides, resveratrol also exhibits structural similarity to the estrogens normally appearing in the human body. A lot of investigations were performed to estimate the potential of resveratrol as concerns its hormonal effects. However, so far no unanimous data have been obtained on the subject. It was shown that resveratrol can exhibit both estrogenic and antiestrogenic effects. Some of the authors suggest that it can have a weak estrogenic activity in the case of the lack of natural hormones, whereas in the presence of natural hormones, the compound has the antagonistic activity [11]. It also seems that the character of the resveratrol effect on the organism varies and is dependent on the age of patients when resveratrol supplementation was introduced.

Another problem examined in our experimental model concerned the concentrations of fundamental trace elements in the serum of rats. The obtained results show that copper concentration in the serum of rats significantly increased, but only in groups supplemented with this mineral (Table 1). No differences found in the copper level in the serum of rats fed with a standard diet could indicate that the neoplastic process does not affect the copper content. However, the literature data show an increase of copper concentration in the serum of cancer patients, including mammary cancer $[14,30]$. Köksoy et al. [30] suggest that the increased copper concentration was most probably due to a release of copper from the cells undergoing necrosis, as a result of inflammatory condition. In addition, those scientists point out to the lowering of copper concentration in the erythrocytes of women suffering from breast cancer. Also, the ceruloplasmin level is increased in many types of cancer, such as leukemia, breast cancer, or gastrointestinal cancer [14]. In healthy cells, copper is located in the cytoplasm, whereas in neoplastic cells, it is mainly located in the intranuclear and perinuclear regions [9]. In addition, copper plays an important role in the process of angiogenesis of neoplastic cells. It is also considered that neoplastic cells may have a tendency to accumulate copper, which even more stimulates angiogenesis [9].

Further investigations showed another interesting phenomenon not connected with the diet, but possibly related to the chemically induced mammary cancer, i.e., the decrease of iron level in the serum (Table 1). One of the aims of the mechanisms regulating homeostasis is to maintain constant the concentrations of trace elements in blood, so considerable iron losses are undoubtedly related to picking it up by other tissues. In our previous investigations [17, 31], we found that the mammary tumor cells were characterized by an increase of iron content by $120-180 \%$ in comparison with iron concentration in healthy cells. Cancer cells undergo intensive cell division and need a considerable amount of iron for their development. In the case of breast cancer, the neoplastic cells have 5 to 15 -fold more transferrin receptors (TfR1) than the cells of healthy mammary gland, which favors the uptake of higher amounts of iron. Another type of transferrin receptors was recently discovered, known as TfR 2 . They are present in many cancer cells and can additionally increase iron absorption [32]. In addition, it was found that the increased iron supply in the diet contributes to a more frequent occurrence of mammary carcinogenesis, induced by a carcinogen in rats, and also of kidney cancer, induced by estrogens in hamsters [33]. This element also initiates the process of carcinogenesis by creating oxidative stress and has a damaging effect on macrophages or an overexpression of IL-6 and IL-8-stimulating the tumor angiogenesis [32]. The iron taking part in the Fenton/Haber-Weiss reaction and due to autooxidation becomes the source of reactive oxygen radicals, in particular of the hydroxyl radical [33]. The investigations showed that the increased iron concentration results in the accumulation in the cells of the products of lipid peroxidation such as malondialdehyde (MDA) and 4-hydroxy-2-nonenal (HNE) [34], which exhibit cytotoxic and mutagenic activities. They cause the oxidative damage of DNA threads, inactivation of many enzymes, and inhibition of DNA and protein synthesis. A biopsy carried out in order to perform the biochemical analysis is an invasive procedure; that is why, investigations were undertaken to determine the changes in iron content in the neoplastic tissue and in the serum. The results obtained did not show any existing correlation in this respect. In patients with anal carcinoma, an increased iron concentration was found, whereas in patients suffering from cancer of the larynx, the iron content was lower, in comparison with the control samples. In patients with oral cavity cancer, it was found that the iron content in the serum does not differ from biochemical standards $[35,36]$. In the case of studies carried out on humans, different dietary habits, medicines, or food supplements can significantly affect the level of mineral components in the blood, irrespectively of the existing disease (at least at the beginning of the disease). The investigations performed on animals allow researchers to eliminate such accidental effects. On the basis of our studies, it can be said that the neoplastic process in the organism significantly decreases iron concentration in the serum, probably directing iron to the developing tumor. 
Iron is an indispensable element for correct catalase activity, so the observed decrease of activity of this enzyme may be connected with the significant decrease of its amount in the blood (Fig. 1).

Another element whose increased content was observed in the serum of rats from the examined groups (standard and coppersupplemented), as compared with the groups of rats that obtained the same diets but without DMBA, was calcium (Table 1). A considerable increase of calcium concentration in the serum, i.e., hypercalcemia, is one of the most common electrolyte imbalances accompanying a neoplastic disease. This disorder occurs most frequently in patients suffering from myeloma and breast cancer (about $40 \%$ patients). Hypercalcemia is due to the excretion of parathormon-related protein (PTHrP) and resorption of osseous tissue [37]. The increased calcium content was found in patients not only in the serum but also in a neoplastic tissue of breast tumors [38, 39]. The accumulation of large quantities of this element by the tissues of mammary cancer results in the appearance of numerous microcalcifications which are a characteristic feature of breast cancer, used in diagnostic mammography $[37,39]$.

Interestingly, no increase in the calcium content was found in the group of rats supplemented with copper in combination with resveratrol, even though it was the group stimulating the majority of changes in mineral content in the serum of rats with mammary cancer, as compared with the rats whose diet was supplemented with minerals, but which obtained no carcinogen (Table 1). Apart from the decrease of iron content and the increase of copper content, a significant decrease of magnesium content and a considerable decrease of zinc content were observed in the serum. The zinc/copper ratio in this study was found to be lower in supplementation groups as compared with the control group because of the significant increases of copper concentrations and decreased or unchanged zinc concentrations (Fig. 2). The characteristic large decrease of the zinc/copper ratio in the serum of the examined rats from the supplementation groups is probably related to the altered metabolism of these elements during a neoplastic disease and to the applied diet (copper excess). Moreover, a major increase in zinc/iron ratio (Fig. 2), which is characteristic of all groups of rats with induced cancer, irrespectively of the applied supplementation, resulted from the discussed earlier drastic decrease of iron content in the serum of the examined rats as compared with the control group. The fact of an altered ratio of elements in the blood of patients suffering from different types of cancer, including breast cancer, irrespectively of the diet, was also observed in other investigations [40, 41].

\section{Conclusions}

Copper intoxication together with the existing neoplastic process accelerated the growth of tumors in rats, probably due to the inhibition of antioxidative defense in their bodies, which was revealed by a decrease of catalase activities in the serum of sick rats. The combination of copper supplementation plus resveratrol, having in mind its potential pro-oxidative activity toward mammary neoplastic cells, did not have a positive protective effect.

In the course of chronic mammary cancer, there occurred a significant decrease of iron content in the serum of rats. This, together with a simultaneous increase of zinc/iron ratio and a decrease of zinc/copper ratio in the serum, may prove to be useful as one of the prognostic factors in breast cancer diagnosis.

Acknowledgments This work was supported by the Ministry of Science and Higher Education grant NN405 358339.

Open Access This article is distributed under the terms of the Creative Commons Attribution License which permits any use, distribution, and reproduction in any medium, provided the original author(s) and the source are credited.

\section{References}

1. Ozcelik D, Uzun H, Nazıroglu M (2012) N-acetylcysteine attenuates copper overload-induced oxidative injury in brain of rat. Biol Trace Elem Res 147(1-3):292-298

2. Johnson F, Giulivi C (2005) Superoxide dismutase and their impact upon human health. Mol Aspects Med 26(4-5):340-352

3. Kirkman HN, Gaetani GF (2007) Mammalian catalase: a venerable enzyme with new mysteries. Trends Biochem Sci 32(1):44-50

4. Nazıroğlu M (2012) Molecular role of catalase on oxidative stressinduced $\mathrm{Ca}(2+)$ signaling and TRP cation channel activation in nervous system. J Recept Signal Transduct Res 32(3):134-141

5. Nazıroğlu M (2009) Role of selenium on calcium signaling and oxidative stress-induced molecular pathways in epilepsy. Neurochem Res 34:2181-2191

6. Rayman MP (2000) The importance of selenium to human health. Lancet 356:233-241

7. Nazıroğlu M, Karaoğlu A, Aksoy AO (2004) Selenium and high dose vitamin $\mathrm{E}$ administration protects cisplatin-induced oxidative damage to renal, liver and lens tissues in rats. Toxicology 195:221-230

8. Formigari A, Irato P, Santon A (2007) Zinc, antioxidant system and metallothionein in metal mediated-apoptosis: biochemical and cytochemical aspects. Comp Biochem Phys C 146:443-459

9. Gupte A, Mumper RJ (2009) Elevated copper and oxidative stress in cancer cells as a target for cancer treatment. Cancer Treat Rev 35:3246

10. Pezzuto JM (2008) Resveratrol as an inhibitor of carcinogenesis. Pharm Biol 46(7-8):443-573

11. Laux MT, Aregullin M, Berry JP, Flanders JA, Rodriguez E (2004) Identification of a p-53-dependent pathway in the induction of apoptosis of human breast cancer cells by the natural product, resveratrol. Altern Complement Med 10(2):235-239

12. Garvin S, Ollinger K, Dabrosin C (2006) Resveratrol induces apoptosis and inhibits angiogenesis in human breast cancer xenografts in vivo. Cancer Lett 231(1):113-122

13. Ahmad A, Syed FA, Singh S, Hadi SM (2005) Prooxidant activity of resveratrol in the presence of copper ions: mutagenicity in plasmid DNA. Toxicol Lett 159(1):1-12 
14. Azmi AS, Bhat SH, Hadi SM (2005) Resveratrol-Cu(II) induced DNA breakage in human peripheral lymphocytes: implications for anticancer properties. FEBS Lett 579(14):3131-3135

15. Wu CF, Yang JY, Wang F, Wang XX (2013) Resveratrol: botanical origin, pharmacological activity and applications. Chin J Nat Med 11(1):0001-0015

16. Pastuszewska B, Ochtabinska A, Morawski A (2000) A note on the nutritional adequacy of stock diets for laboratory rats and mice. $\mathrm{J}$ Anim Feed Sci 9(3):533-542

17. Skrajnowska D, Bobrowska B, Tokarz A, Kuras M, Rybicki P, Wachowicz M (2011) The effect of zinc- and copper sulphate supplementation on tumor and hair concentrations of trace elements ( $\mathrm{Zn}$, $\mathrm{Cu}, \mathrm{Fe}, \mathrm{Ca}, \mathrm{Mg}, \mathrm{P})$ in rats with DMBA-induced breast cancer. Pol J Environ Stud 20(6):1585-1592

18. Bobrowska-Korczak B, Skrajnowska D, Tokarz A (2011) Effect of $\mathrm{Cu}$ supplementation on genome instability in chemically-induced mammary carcinogenesis in the rat. J Biomed Sci 18:95

19. Barros ACSD, Muranaka ENK, Jo Mori L, Pelizon CHT, Giocondo IKG, Pinotti JA (2004) Induction of experimental mammary carcinogenesis in rats with 7,12-dimethylbenz(a)anthracene. Rev Hosp Clín Fac Med S Paulo 59(5):257-261

20. Muqbil I, Banu N (2006) Enhancement of pro-oxidant effect of 7,12dimethylbenz(a)anthracene (DMBA) in rats by preexposure to restraint stress. Cancer Lett 240(2):213-220

21. Cao Y, Wang J, Henry-Tillman R, Klimberg VS (2001) Effect of 7, 12-dimethylbenz $[a]$ anthracene (DMBA) on gut glutathione metabolism. J Surg Res 100(1):135-140

22. Bobrowska B, Tokarz A, Białek S, Seweryn M (2011) Effect of dietary supplementation on the prognostic value of urinary and serum 8 -isoprostaglandin F2 $\alpha$ In chemically-induced mammary carcinogenesis in the rat. Lipids in Health and Dis 10:40

23. Gupte A, Mumper RJ (2007) Copper chelation by D-penicillamine generates reactive oxygen species that are cytotoxic to human leukemia and breast cancer cells. Free Radical Bio Med 43(9):1271-1278

24. Bobrowska B, Tokarz A, Grynkiewicz G, Bialek S, Matysiak M, BatErdene T (2009) The effect of polyphenols on markers of oxidative damage and DMBA-induced carcinogenesis in rats. J Food Lipid 16(1):103-112

25. Góth L, Lenkey A, Bigler WN (2001) Blood catalase deficiency and diabetes in Hungary. Diabetes Care 24(10):1839-1840

26. Sinha R, Singh R, Mehrotra S, Singh RK (2009) Implications of free radicals and antioxidant levels in carcinoma of the breast: a neverending battle for survival. Indian J Cancer 46(2):146-150

27. Hanimoglu H, Tanriverdi T, Kacira T, Sanus GZ, Atukeren P, Aydin S, Tunali Y, Gumustas K, Kavnar MY (2007) Relationship between DNA damage and total antioxidant capacity in patients with transitional meningioma. Clin Neurol Neurosur 109(7):561-566
28. Palma JM, Sandalio LM, Corpas FJ, Romero-Puertas MC, McCarthy I, del Rio LA (2002) Plant proteases, protein degradation and oxidative stress: role of peroxisomes. Plant Physiol Bioch 40(6-8):521-530

29. Hager J, El Ferjani E (2004) Effect of copper excess on superoxide dismutase, catalase, and peroxidase activities in sunflower seedlings (Helianthus annuus L.). Acta Physiol Plant 26(1):29-35

30. Köksoy K, Kavas GO, Akçil E, Kocatürk PA, Kara S, Ozarslan C (1997) Trace elements and superoxide dismutase in benign and malignant breast diseases. Breast Cancer Res Treat 45(1):1-6

31. Skrajnowska D, Bobrowska B, Tokarz A, Kuras M (2012) The effect of copper and resveratrol on hair mineral concentrations in rats with DMBA-induced mammary cancer. Bromat Chem Toksykol 3:580 585

32. Gurzau ES, Neagu C, Gurzau AE (2003) Essential metals - case study on iron. Ecotoxicol Environ Safe 56(1):190-200

33. Huang $X$ (2003) Iron overload and its association with cancer risk in humans: evidence for iron as a carcinogenic metal. Mutat Res 533(12):153-171

34. Schriner SE, Linford NJ, Martin GM, Treuting P, Ogburn CE, Emond M, Coskun PE, Ladiges W, Wolf N, Van Remmen H, Wallace DC, Rabinovitch PS (2005) Extension of murine life span by over expression of catalase targeted to mitochondria. Science 308:1909-1911

35. Milde D, Novák O, Stuka V, Vyslouil K, Macháek J (2001) Serum levels of selenium, manganese, copper, and iron in colorectal cancer patients. Biol Trace Elem Res 79(2):107-114

36. Bhattathiri VN (2001) Relation of erythrocyte and iron indices to oral cancer growth. Radiother Oncol 59(2):221-226

37. Szyszka-Barth K, Spychalski Ł, Hałas J, Bryl M, Ramlau R (2011) Hypercalcemia of malignancy: patomechanism, symptoms and treatment. Onkol Pol 14(2):103-106

38. Pasha Q, Malik SA, Iqbal J, Shaheen N, Shah MH (2008) Comparative evaluation of trace metal distribution and correlation in human malignant and benign breast tissues. Biol Trace Elem Res 125(1):30-40

39. Kubala-Kukus A, Banas D, Braziewicz J, Gozdz S, Majewska U, Pajek M (2007) Analysis of elemental concentration censored distributions in breast malignant and breast benign neoplasm tissues. Spectrochim Acta B 62:695-701

40. Zowczak M, Iskra M, Torlinski L, Cofta S (2001) Analysis of serum copper and zinc concentrations in cancer patients. Biol Trace Elem Res 82:1-8

41. Gümüș M, Yüksel H, Evliyaoğlu O, Kapan M, Böyük A, Önder A, Aldemir M (2011) Effects of ellagic acid on copper, zinc, and biochemical values in serum and liver of experimental cholestatic rats. Biol Trace Elem Res 143(1):386-393 